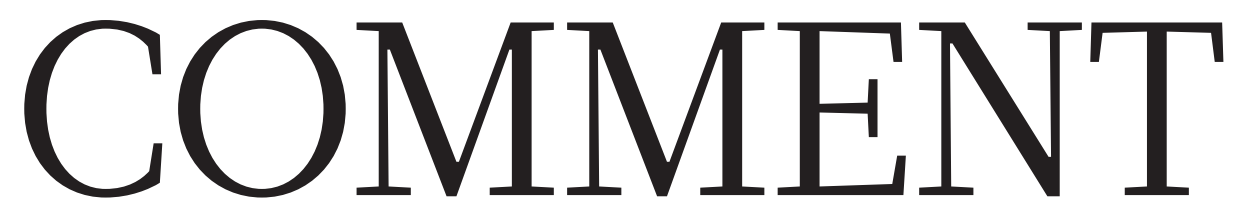

GOVERNANCE Treat land as a global commons, legally and conceptually $\mathbf{p . 2 8}$

CRISPR Tantalizing memoir from gene-editing pioneer Jennifer Doudna p.30

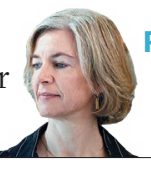

PUBLISHING Creative ways

to stamp out and punish fake reviewing $\mathbf{p . 3 3}$
TAXONOMY Adopt stable identifiers for collection specimens p.33

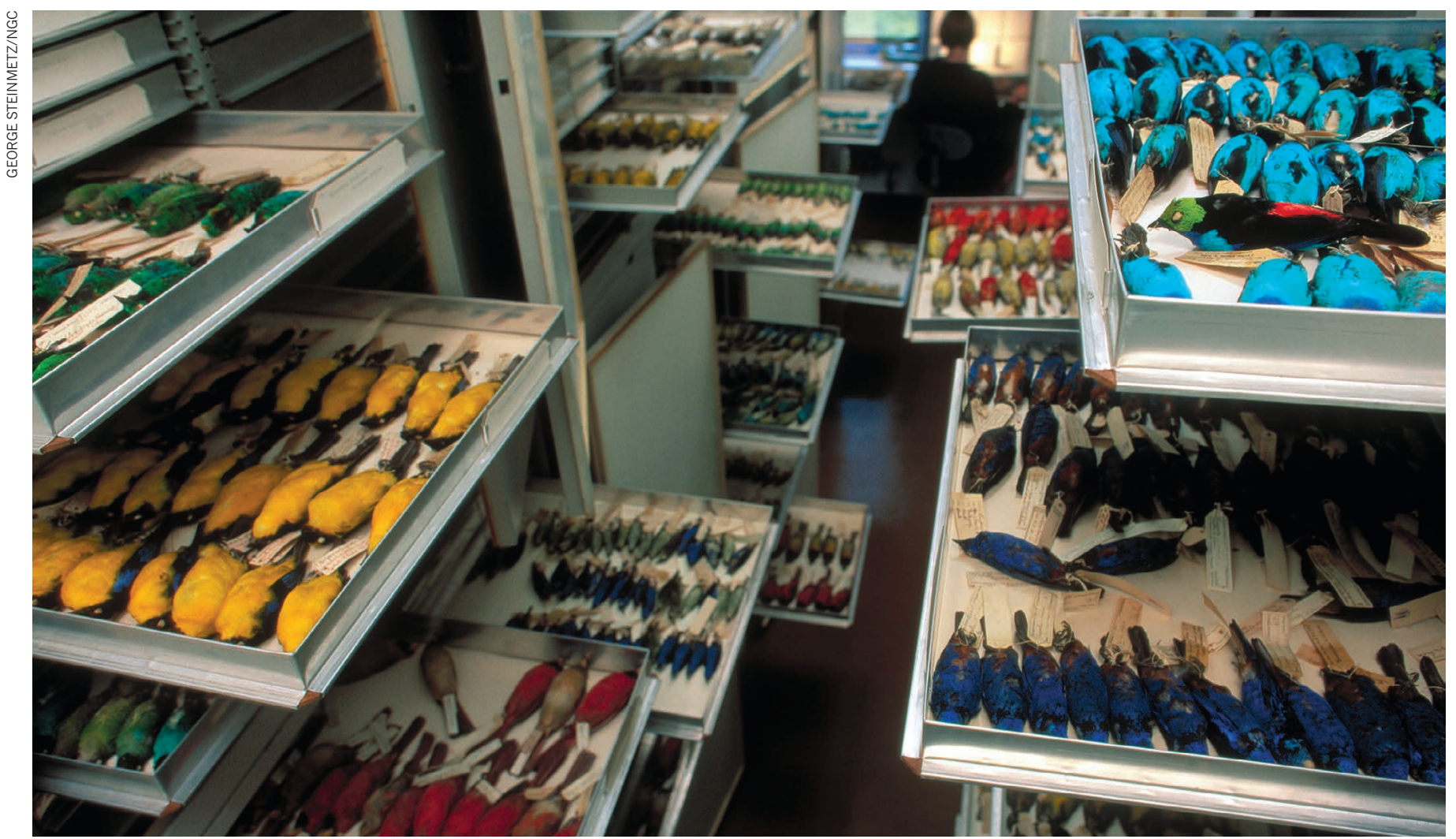

Part of the vast ornithology collection at the American Museum of Natural History.

\title{
Taxonomy anarchy hampers conservation
}

The classification of complex organisms is in chaos. Stephen T. Garnett and Les Christidis propose a solution.

$\mathrm{T}$ The assumption that species are fixed entities ${ }^{1}$ underpins every international agreement on biodiversity conservation, all national environmental legislation and the efforts of many individuals and organizations to safeguard plants and animals. Yet for a discipline aiming to impose order on the natural world, taxonomy (the classification of complex organisms) is remarkably anarchic.

There is reasonable agreement among taxonomists that a species should represent a distinct evolutionary lineage. But there is none about how a lineage should be defined. 'Species' are often created or dismissed arbitrarily, according to the individual taxonomist's adherence to one of at least 30 definitions $^{2}$. Crucially, there is no global oversight of taxonomic decisions - researchers can 'split or lump' species with no consideration of the consequences.
We contend that the scientific community's failure to govern taxonomy threatens the effectiveness of global efforts to halt biodiversity loss, damages the credibility of science and is expensive to society.

To address the problem, we propose that the governance of the taxonomy of complex organisms be brought under the purview of the International Union of Biological Sciences (IUBS). This is the umbrella body for biology within 
the International Council for Science, the highest-level organization for global scientific governance.

\section{FREE-FOR-ALL}

The lack of universal rules for taxonomy has many consequences. A major issue is differences in tradition between classes. Many mammalian taxonomists use the phylogenetic species concept (PSC): two populations are listed as distinct species if they have a common ancestor but differ physically or genetically ${ }^{2}$. Meanwhile, many bird taxonomists favour the more conservative biological species concept - the idea that true species should not normally produce fertile hybrids ${ }^{2}$. An estimate published last year suggests that the number of bird species would more than double were bird taxonomists to adopt the PSC ${ }^{3}$.

Depending on which species concept is used, one class can seem more threatened than another, and so receive a bigger slice of conservation funding. In 2012, for instance, roughly the same amount of spending was dedicated to birds and mammals, per species, under the US Endangered Species Act ${ }^{4}$. But if mammals are more finely split than birds, that means more money is being funnelled towards the protection of mammalian genetic diversity overall. Paradoxically, finer splitting could also make certain species more vulnerable. Safari hunters currently achieve the 'spiral horned grand slam' by killing just nine types of antelope. Recent developments in taxonomy could see them wanting to kill 25 , and targeting smaller populations to do so.

A second issue is that conservation legislation often fails to keep pace with changes to how animals and plants are classified. For example, changes to taxonomy since Chinese wildlife legislative lists were last updated in 1989 have left 25 species listed under the Convention on International Trade in Endangered Species of Wild Fauna and Flora (CITES) exposed to illegal trade ${ }^{5}$. It can also affect countries' biodiversity tallies under the Convention on Biological Diversity. Splitting species into smaller units means that more are likely to meet the definitions of being threatened, and so may increase a country's overall count of threatened species. The application of the PSC to the 'near threatened' central Asian argali wild sheep (Ovis ammon), turned one species into nine, and overnight Kazakhstan had five mountain sheep species in need of protection, not just one ${ }^{6}$.

Nationally, the splitting or lumping of species protected by law can affect investment and land use, and even foster doubts about science among the public and policymakers. In an ongoing battle, developers seeking access to valuable land are proposing that a bird, the coastal California gnatcatcher (Polioptila californica californica), does not warrant protection. They argue that DNA evidence indicates that it is not a valid taxon.

More broadly, a single taxonomic paper can affect whole conservation programmes, tourist enterprises and employment opportunities. Conservationists and others deeply attached to a particular species construct can have the object of their attachment redefined out of existence or inextricably subdivided. Take the proposal in 2000 to lump the Florida panther (Puma concolor coryi) with the widespread North American cougar ${ }^{7}$. Had it

"Vagueness is not
conservation." been universally accepted, it would have threatened the subspecies' conservation.

The taxonomists driving such changes are not accountable to anyone other than their academic peers. And peer review provides few constraints. Reviewers of taxonomic papers tend to comment on the techniques used to evaluate organisms, rather than on definitions. In short, other stakeholders have no objective criteria against which to argue the case for a different outcome and no globally recognized avenue for appeal.

\section{GOOD GOVERNANCE}

More than a decade ago, a group of conservation scientists identified the need for a stable and agreed taxonomy for conservation ${ }^{8}$. No action has been taken.

Unlike the classification of organisms, the naming of animals and plants has been effectively governed by two branches of the IUBS for more than a century: namely, the International Commission on Zoological Nomenclature (ICZN) and the International Association for Plant Taxonomy (IAPT). Both organizations aim to ensure that every scientific name of an animal or plant is unique.

Yet neither organization takes any responsibility for how species are defined. Indeed, a collaboration between the IUBS and the International Union of Microbiological Societies to create a common code for naming animals, plants and bacteria explicitly states:
"Nothing in this Code may be construed to restrict the freedom of taxonomic action" ". As long as taxonomists follow the naming rules, they can define species however they wish.

In our view, the IUBS should create a process that does exactly what that effort avoids - restrict the freedom of taxonomic action. And it should do so by creating boundaries for species (and other taxonomic units) that can be applied consistently across multiple life forms. The IUBS is the only body with the global reputation and remit to develop a system of taxonomic governance that is likely to be adopted internationally. (The naming rules of the ICZN and IAPT are followed universally.)

Fortunately, a model for effective and International Committee on Taxonomy of Viruses has the final say on the classification of viruses. This committee ensures that both naming rules and definitions of species are applied consistently, and maintains a global list of species (currently around 4,400 are listed; see go.nature.com/2rhp8af).

Crucially, the microbiological committees acknowledge that species definitions are at least partly arbitrary human divisions of natural continua ${ }^{2}$. This is crucial to limiting confusion and squabbling (see T. Pape Nature 537, 307; 2016). They also have a judicial commission, which oversees subcommittees that actually apply the rules to groups of taxa.

\section{FOUR STEPS}

To roll out this model more widely, four steps need to be taken.

First, the IUBS must agree to take decisive leadership on taxonomy, with the support of organizations that could benefit most, such as the CITES Secretariat and the International Union for Conservation of Nature.

Second, the IUBS should create a taxonomic commission to establish what rules (if any) should be applied across all life forms and, if taxon-specific definitions need to be developed, what those should be. respected taxonomic governance exists. The

\section{MIX 'N' MATCH}

Different organizations recognize different numbers of bird species, mostly because they use different definitions for what constitutes a species.

11,500

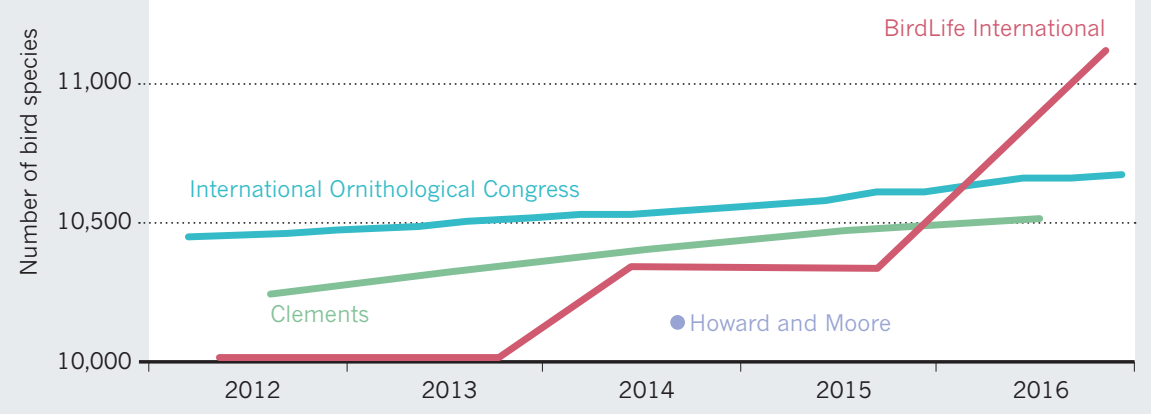




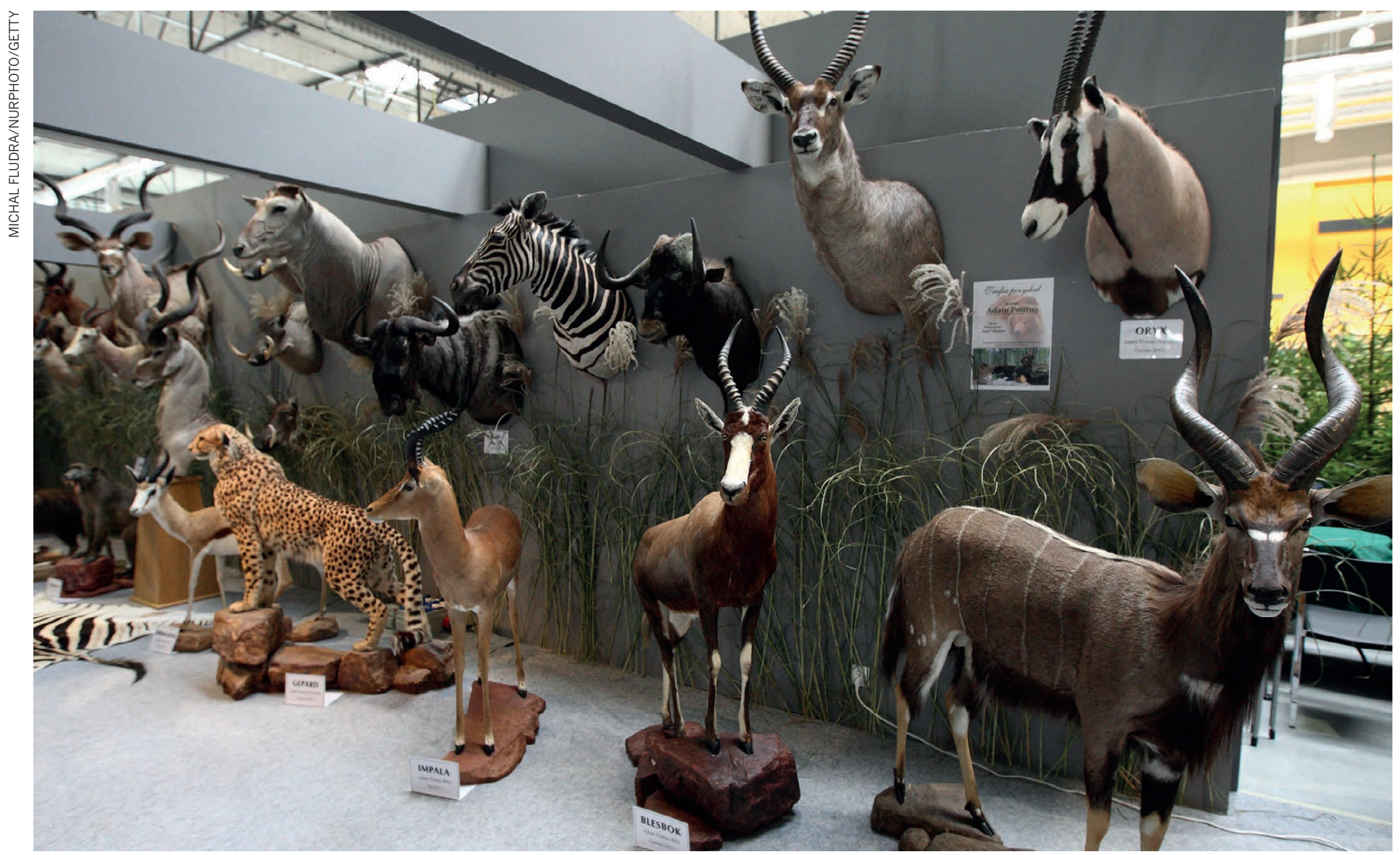

Developments in taxonomy could see safari hunters killing 25 types of antelope, instead of the previous 9 , to achieve the 'spiral horned grand slam'.

For instance, agreed differences in calls and songs could help to delineate species of birds and primates; for fungi, genetic barcodes could be used. Such differences must be explicitly stated and agreed.

Third, the taxonomic commission needs to establish subcommittees for agreed subsets of life, such as amphibians or arachnids. These subcommittees would review taxonomic papers for compliance with agreed standards. On the basis of that review process, they would create the first standardized global species lists for groups such as birds or mammals, a process currently assumed by various organizations (see 'Mix 'n' match'), all competing for legitimacy.

Fourth, the taxonomic commission also needs to establish a judicial committee. This would be the final arbiter between subcommittees, responsible for upholding the rules and adjusting them as required when new knowledge becomes available.

In our view, many taxonomists would welcome such a governance structure. Reducing the time spent dealing with different species concepts would probably make the task of describing and cataloguing biodiversity more efficient.

\section{DEFENSIBLE BOUNDARIES}

Scientists have repeatedly demonstrated the capacity to create sophisticated and equitable governance - even if the strengths and weaknesses of specific approaches continue to be debated (see D. Sarewitz Nature 522, 413-414; 2015). Take the ongoing deliberations of the International Union of Geological Sciences about whether the anthropocene should be recognized as an official subdivision of the geological record (see Nature 519, 144-147; 2015). In 2016, geoscientists argued that social scientists including anthropologists and historians should be among the three-dozen people who will make the decision about the Anthropocene on behalf of humanity $^{10}$. The debate's vigour is healthy, and it should eventually be resolved at a conference in 2020.

As with the Anthropocene, decisions about how to partition life are as much a concern of politics and ethics as of biology. If species delineations are at least partly arbitrary, deliberations must draw on expertise beyond taxonomy, morphology, systematics and genetics. Lawyers should be included to ensure that any definition can withstand legal challenge. And anthropologists and sociologists could advise on social equity, given that taxonomic decisions can dramatically affect people's livelihoods, particularly in low-income countries.

"No one definition has satisfied all naturalists; yet every naturalist knows vaguely what he means when he speaks of a species," wrote Charles Darwin in On the Origin of
Species in 1859. Despite all the progress in understanding evolution and speciation since that time, remarkably little has changed when it comes to definitions. But vagueness is not compatible with conservation. To protect biodiversity, laws need to compartmentalize it, and those compartments must have legally defensible boundaries.

Stephen T. Garnett is a professor at the Research Institute for the Environment and Livelihoods, Charles Darwin University, Darwin, Australia. Les Christidis is a professor and dean of graduate studies at Southern Cross University, Coffs Harbour, Australia.

e-mails: stephen.garnett@cdu.edu.au; les. christidis@scu.edu.au

1. Smith, I. A. The Intrinsic Value of Endangered Species (Routledge, 2016).

2. Zachos, F. E. Species Concepts in Biology (Springer, 2016).

3. Barrowclough, G. F., Cracraft, J., Klicka, J. \& Zink, R. M. PLOS ONE 11, e0166307 (2016).

4. Evans, D. M. et al. Issues in Ecology (Ecological Society of America, 2016).

5. Zhou, Z.-M. et al. Conserv. Lett. 9, 313-315 (2016).

6. Castelló, J. R. Bovids of the World (Princeton Univ. Press, 2016).

7. Culver, M., Johnson, W. E., Pecon-Slattery, J. \& O'Brien, S. J. J. Hered. 91, 186-197 (2000).

8. Isaac, N. J. B., Mallet, J. \& Mace, G. M. Trends Ecol. Evol. 19, 464-469 (2004).

9. Greuter, W. et al. Taxon 60, 201-212 (2011).

10.Ellis E. C. et al. Nature 540, 192-193 (2016). 